\title{
Spatial synchrony of breeding success in the black-legged kittiwake Rissa tridactyla reflects the spatial dynamics of its sandeel prey
}

\author{
Agnes B. Olin ${ }^{1,2, *}$, Neil S. Banas ${ }^{1}$, Peter J. Wright ${ }^{3}$, Michael R. Heath ${ }^{1}$, \\ Ruedi G. Nager ${ }^{2}$
}

${ }^{1}$ University of Strathclyde, Livingstone Tower, Glasgow G1 1XH, UK

${ }^{2}$ University of Glasgow, Graham Kerr Building, Glasgow G12 8QQ, UK

${ }^{3}$ Marine Scotland Science, Marine Laboratory, Aberdeen AB11 9DB, UK

\begin{abstract}
Synchrony in demographic rates between spatially disjunct populations is a widespread phenomenon, although the underlying mechanisms are often not known. This synchrony and its spatial patterns can have important consequences for the long-term persistence of metapopulations and can also be used to infer drivers of population dynamics. Here, we examined spatial patterns of synchrony in the breeding success of black-legged kittiwakes Rissa tridactyla in the UK, using an extensive dataset on kittiwake breeding success and 2 different ways of measuring synchrony: one reflecting synchrony in inter-annual fluctuations only $\left(r_{\text {diff }}\right)$ and one reflecting synchrony in both inter-annual fluctuations and long-term trends $(r)$. We found that betweencolony synchrony in breeding success decreased with distance up to just over $200 \mathrm{~km}$ but that some colony pairs showed stronger or weaker synchrony than expected based on distance. This was also reflected in the configuration of spatially coherent clusters of kittiwake colonies with synchronous breeding success. Further, we compared the support for different drivers of these spatial patterns, including trophic interactions and weather conditions. We found that the spatial dynamics of the kittiwakes' main prey in this region, the lesser sandeel Ammodytes marinus, appeared to play some role in generating synchrony in long-term patterns, but their role in generating synchrony in inter-annual fluctuations was less clear. The study shows that examining spatial patterns in synchrony can provide useful information for inferring potential drivers and the spatial scale over which they are acting.
\end{abstract}

KEY WORDS: Spatial population dynamics - Spatial autocorrelation - Seabird - Sand lance * North Sea $\cdot$ Forage fish $\cdot$ Cluster analysis

\section{INTRODUCTION}

A wide variety of taxa show spatial synchrony, defined as 'coincident changes in the abundance or other time-varying characteristics of geographically disjunct populations' (Liebhold et al. 2004). Synchrony is an important aspect of population dynamics as the degree to which populations show synchronised dynamics is a key determinant of long-term

*Corresponding author: agnes.olin@glasgow.ac.uk metapopulation persistence (Engen et al. 2002) and may have important implications for community dynamics and ecosystem function (Stenseth et al. 2002). Several mechanisms may act to generate synchrony, including trophic interactions with other species that show spatial synchrony (e.g. Ims \& Andreassen 2000, Ripa \& Ranta 2007, Haynes et al. 2009), mixing between close-by populations through dispersal (e.g. Sutcliffe et al. 1996, Schwartz et al.

(C) The authors 2020. Open Access under Creative Commons by Attribution Licence. Use, distribution and reproduction are unrestricted. Authors and original publication must be credited. 
2002) or dependence on some spatially autocorrelated external factor such as weather conditions (e.g. Moran 1953, Grenfell et al. 1998, Post \& Forchhammer 2002, Grøtan et al. 2005). The patterns of synchrony may be further modified by spatial variation in the dynamics of density dependence (e.g. Liebhold et al. 2006). Different mechanisms may be expected to generate different geographical patterns of synchrony. Comparing these expected patterns with observed spatial patterns in population synchrony, including detailed geographic patterns (Walter et al. 2017) as well as how between-population synchrony declines with distance (Bjørnstad \& Falck 2001), can thus help us to identify factors that drive population dynamics and at what spatial scale they operate (Walter et al. 2017). This approach has, for example, been used previously to identify large-scale climate fluctuations as a driver of population dynamics in caribou Rangifer tarandus and muskoxen Ovibos moschatus in Greenland (Post \& Forchhammer 2002). As such, it can provide useful information for species conservation by identifying causes of population declines and the spatial scales over which management efforts may be needed (e.g. O'Hanlon \& Nager 2018).

One species in which spatial synchrony has been investigated is the black-legged kittiwake Rissa tridactyla (hereafter 'kittiwake'), a colonial, pelagic seabird species that has recently shown such steep declines that it was globally red listed (BirdLife International 2018). Over the scale of its full distribution across the Northern Hemisphere, synchrony in the fluctuations of colony sizes has generally been nonexistent or very low, apart from a synchronised decline during a period of rapid ocean warming (Descamps et al. 2017). Similarly, a study looking at smaller scale synchrony, using colonies along the coast of Norway, found no evidence that colony sizes fluctuated in unison (Sandvik et al. 2014). However, synchrony has been identified in kittiwake breeding success in the UK and Ireland, where colonies formed geographically distinct clusters in which breeding success fluctuated in unison (Furness et al. 1996, Frederiksen et al. 2005). Furness et al. (1996) hypothesised that the observed clusters were the result of a response to the independent dynamics of aggregations of lesser sandeels Ammodytes marinus (hereafter 'sandeels'), the main prey of kittiwakes in large parts of the UK. The sandeel is also an important prey for many other top predators in this area (Furness \& Tasker 2000), and climate-driven declines in the abundance and size of the sandeel is thought to be an important contributing factor to declines of kittiwakes and other sandeel-eating seabirds in large parts of the UK (MacDonald et al. 2015). In line with the hypothesis developed by Furness et al. (1996), Frederiksen et al. (2005) found that the kittiwake breeding success synchrony clusters corresponded roughly to distinct aggregations of larval and settled sandeels. While this provides support for the hypothesis, this is a coarse way of representing sandeel dynamics compared to what we now know about sandeel spatial structure. Furthermore, no alternative mechanisms that could potentially generate similar patterns were examined and ruled out.

Of the potential mechanisms that could generate the observed spatial patterns in kittiwake breeding success synchrony, spatial patterns in the synchrony of a trophically interacting species or spatial patterns in the synchrony of environmental conditions appear most plausible. There is no evidence of any densitydependent effects acting on kittiwake breeding success in this area (Frederiksen et al. 2005), and this is thus unlikely to contribute to the observed synchrony patterns. Further, while dispersal may synchronise fluctuations in abundance through dispersers from one population spreading to multiple other populations and thus creating a synchronised increase (e.g. Schwartz et al. 2002), dispersal would not be expected to have a similar effect on a demographic rate such as breeding success. In terms of trophic interactions and environmental conditions, there are multiple alternative drivers. Weather conditions, primarily wind (e.g. Christensen-Dalsgaard et al. 2018a,b) and rain (Alvestad 2015), may impact breeding success through effects on thermoregulation and foraging conditions. More extreme weather events may also result in nests being washed away or dislodged (e.g. Newell et al. 2015). As a result, weather, which shows strong spatial autocorrelation, could be capable of generating spatial patterns in kittiwake breeding success synchrony. Another driver of kittiwake breeding success is predation. Kittiwake eggs and chicks are targeted by a range of predators (e.g. Galbraith 1983, Collins et al. 2014), but great skuas Stercorarius skua (hereafter 'skua') are likely the only ones able to have a substantial impact on productivity (see Heubeck 2002, Votier et al. 2004). Skuas are only present in the north of the UK and this spatial variation in presence, together with the ability of predation to induce synchrony (e.g. Ims \& Andreassen 2000), means that skua dynamics could potentially generate spatial patterns in kittiwake breeding success synchrony. Finally, as hypothesised by Furness et al. (1996) and Frederiksen et al. (2005), it is possible that sandeels, which show clear spatial patterns 
in synchrony, are responsible for the observed patterns. Sandeels have a strong preference for a certain depth and sediment type which shows a patchy distribution (Wright et al. 2000, Holland et al. 2005), and as a result, aggregations of sandeels have a patchy distribution themselves (e.g. Jensen et al. 2011). As sandeels show very low levels of post-settlement movement, dispersal of larvae is the main process connecting sandeel grounds (Wright et al. 2019). This, together with external drivers of sandeel demographic rates such as zooplankton conditions (e.g. Régnier et al. 2017, MacDonald et al. 2018), temperature (e.g. Rindorf et al. 2016, Wright et al. 2017) and predation (e.g. Frederiksen et al. 2007), likely act as driving forces of synchrony in sandeel dynamics. Synchrony in sandeel abundances has been shown to decline with distance (Wright et al. 2019). However, likely largely as a result of patterns of larval transport, this decline is not uniform, and areas that are not hydrographically well-connected show low levels of synchrony (ICES 2017, Wright et al. 2019).

The aim of this study is to examine spatial patterns in the synchrony of breeding success in British kittiwakes and to revisit the hypothesis of Furness et al. (1996) and Frederiksen et al. (2005) that synchrony in kittiwake breeding success in the UK is driven by the spatial structure of their sandeel prey. We build on previous work by utilising recent advancements in the understanding of sandeel spatial structure, by adding 15 further years of data on kittiwake breeding success and by also examining alternative hypotheses. To characterise spatial patterns in kittiwake breeding success synchrony, we (1) examine the relationship between breeding success synchrony and between-colony geographical distance, (2) map out the spatial configuration of colony pairs showing stronger or weaker synchrony than expected based on distance and (3) examine geographical patterns in synchrony further using a cluster analysis. Following this, we (4) investigate potential mechanisms for generating the observed spatial patterns in kittiwake breeding success synchrony, focusing on sandeel spatial structure, skua predation and weather conditions. We do this using 2 different metrics of synchrony, focusing mainly on one reflecting synchrony in inter-annual fluctuations only $\left(r_{\text {diff }}\right)$ but also looking at one reflecting synchrony in both inter-annual fluctuations and longterm trends $(r)$. The study will help to identify largescale drivers of breeding success in the rapidly declining population of British kittiwakes, and the spatial scales over which they may be acting. On a broader scale, the study, having access to long-term spatially resolved data, also helps us to further understand which drivers may act to generate spatial patterns in synchrony.

\section{MATERIALS AND METHODS}

\subsection{Kittiwake breeding success data}

Our study area covered the part of the UK where sandeel is an important prey item for kittiwakes (based on Furness \& Tasker 2000) and we could make well-founded predictions for sandeel synchrony patterns (see Section 2.4). This area included the north and east coast of mainland UK, as well as Shetland and Orkney (Fig. 1a). For this area, data on breeding success (average number of fledglings produced per nest per year in each colony) were accessed from the Seabird Monitoring Programme website (https://app.bto.org/seabirds, accessed 27 January 2019) and from the Centre for Ecology and Hydrology (data from the Isle of May, Newell et al. 2016). The same protocol (Walsh et al. 1995) was used at all colonies to estimate breeding success. We excluded estimates based on fewer than 40 nests as smaller samples may not be representative as a result of demographic stochasticity. The study period covered the years 1986 to 2018, as breeding success was not monitored in many colonies before 1986.

\subsection{Synchrony in breeding success}

Synchrony can be measured with different metrics that emphasise different aspects (Buonaccorsi et al. 2001). Here, we measure synchrony as the Pearson correlation of the differences in breeding success between consecutive years, $r_{\text {diff. }}$ This metric is good at capturing the degree to which 2 time series move together on an annual scale, closely following the textbook definition of synchrony (Buonaccorsi et al. 2001). As such, it does not reflect synchrony in longterm trends, which reduces the risk of inferring high synchrony between colonies that show similar longterm trends for different reasons. However, similar long-term signals may also tell us something about mutual drivers (Pyper \& Peterman 1998), and this is not picked up by $r_{\text {diff. }}$. For this reason, we also run a parallel analysis where we use the Pearson correlation $r$ of the untransformed breeding success time series for each colony pair as an alternative measure of synchrony. 

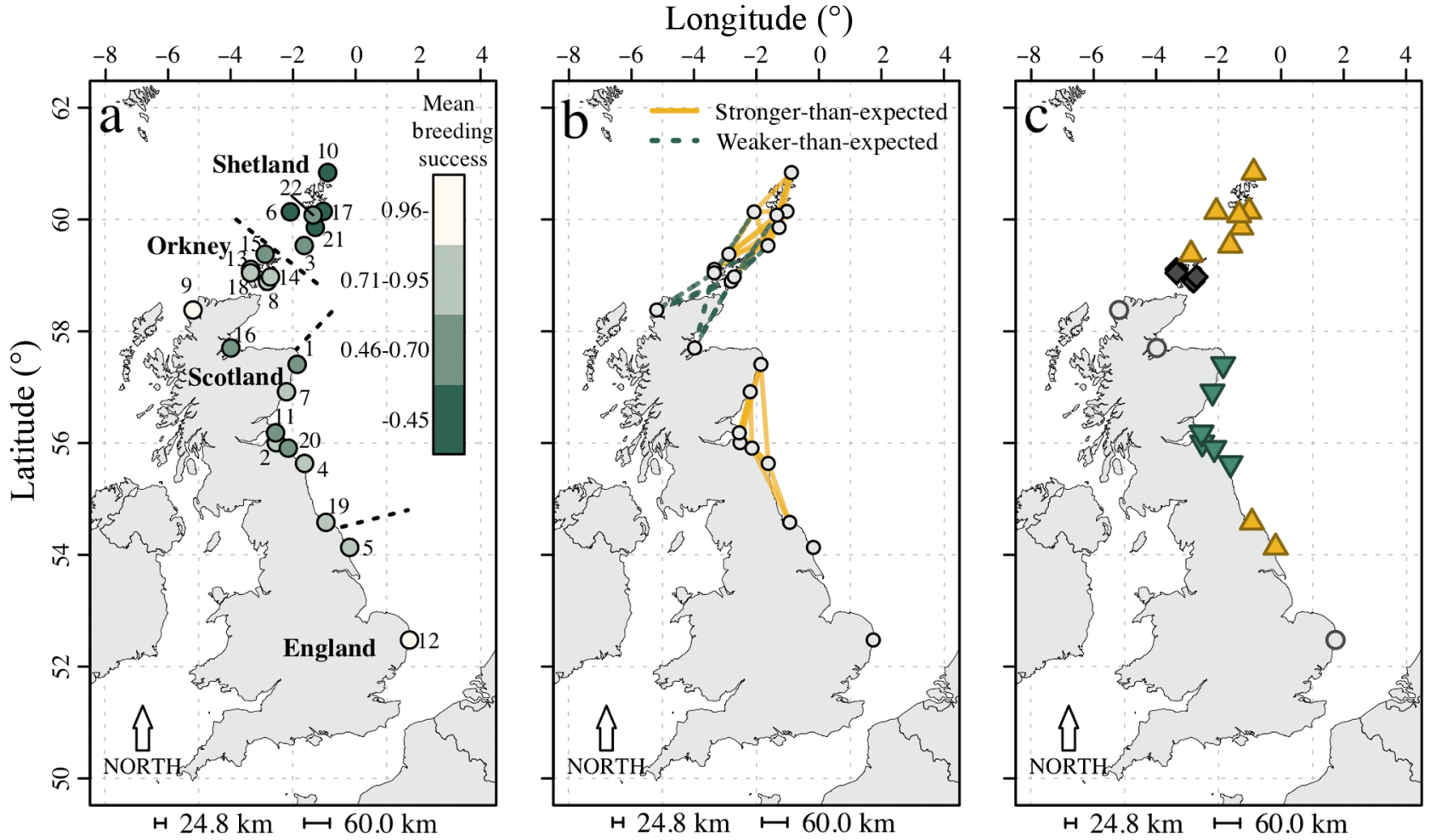

Fig. 1. (a) Black-legged kittiwake colonies included in the study, colour-coded by the mean breeding success during the study period (1986-2018). Place names referred to in the text are included for reference. The numbers correspond to colonies listed in Table 1. Dashed lines: approximate borders between sandeel sub-population regions (see Section 2.4). (b) Weaker (negative residuals from relationship in Fig. 2) and stronger (positive residuals from relationship in Fig. 2) synchrony than expected based on distance for colonies closer than $200 \mathrm{~km}$ apart (the synchrony-distance relationship was unclear beyond this distance, see Section 3.1.1). (c) Combined results from the cluster analysis. Round grey symbols: colonies assigned to different clusters by the different algorithms (see Table S2 in the Supplement). The other coloured symbols indicate clusters that were consistently identified by all algorithms. All maps were produced with the R-package rworldmap (South 2011). The scale bars correspond to the average length $(24.8 \mathrm{~km})$ and the average estimated maximum length $(60.0 \mathrm{~km})$ of a kittiwake foraging trip based on a meta-analysis of foraging ranges (Thaxter et al. 2012)

We only included colonies that had a minimum average of 15 occasions of overlapping estimates of breeding success in 2 consecutive years with all other colonies (see Table S1 in the Supplement at www.int-res.com/articles/suppl/m638p177_supp.pdf for values for each colony pair). This cut-off value was based on an examination of how much the estimated $r_{\text {diff }}$ changed as data points were removed (see Fig. S1 in the Supplement) balanced against the number of colonies that could be included and their geographical spread. In total, 22 colonies spread out over the entire area of interest (Fig. 1a) had sufficient data (average $27.1 \mathrm{yr}$ of data per colony, range 17 to 31). Most colonies had missing years distributed throughout the time period, but a few colonies had a longer sequence (maximum $10 \mathrm{yr}$ ) missing at the start (Colony 22) or at the end (Colonies 9, 14, 15, 18, 19, see Fig. 1a and Table 1 to identify colonies).

\subsection{Spatial patterns in synchrony}

\subsubsection{Effect of geographical distance on synchrony}

To establish the spatial scale of synchrony, we determined the relationship between the betweencolony geographical distance and the between-colony breeding success synchrony. As similarity in conditions and connectivity between colonies is more likely to depend on distance along the coast rather than the distance across landmasses, we used along-coast distance as our distance metric. This was calculated as the shortest path between colonies without allowing the crossing of landmasses, using the function gridDistance in the package raster (Hijmans 2018) in $R$ 3.5.2 (R Core Team 2018, used for all analyses). To assess how synchrony declined with distance, we fitted a cubic smoothing spline, thus making no prior assumptions about the shape of the relationship (Bjørn- 
stad \& Falck 2001). This was done using the Sncf function from the R-package ncf (Bjørnstad 2019), where uncertainty was estimated with a bootstrapping approach based on 10000 resamples.

\subsubsection{Deviations from the distance-synchrony relationship}

Next, we examined the spatial patterns of colony pairs showing stronger or weaker synchrony in breeding success than what was expected based on distance. To do this, we identified colony pairs falling above (positive residuals) and below (negative residuals) the $99 \%$ bootstrapping confidence interval of the estimated distance-synchrony spline and then visualised these higher-than-expected and lower-than expected linkages on a map. We only used colony pairs separated by a distance for which there was a clear relationship between synchrony and distance.

\subsubsection{Cluster analysis}

A cluster analysis was carried out to further examine spatial patterns in breeding success synchrony. Colonies were clustered based on the similarity distance between each colony pair, calculated as 1 synchrony (perfect synchrony gives a distance of 0 , no correlation a distance of 1 and perfect asynchrony a distance of 2). As the final cluster structure can be sensitive to the choice of clustering algorithms, we used several different algorithms to obtain a more robust understanding of the cluster structure. Using functions from the R-package cluster (Maechler et al. 2018), we carried out hierarchical agglomerative clustering (agnes), using the Ward (1963) method to measure similarity between clusters, divisive hierarchical clustering (diana), partitional clustering (pam), and fuzzy clustering (fanny). In fanny, the degree of belonging to each of a defined number of clusters is calculated, giving us a better understanding of which colonies may form the core of a cluster, and which colonies are instead showing similarities with several clusters.

All algorithms require the number of clusters, $k$, to be specified. To do this we used 3 metrics to assess the strength of the cluster structure for different values of $k$ for each algorithm, the within-cluster sum of squares, which measures within-cluster variation, the gap statistic, which compares the within-cluster variation for each value of $k$ with the expected values under a null reference distribution, and the average silhouette width, which compares the average similarity of colonies to other colonies within their own cluster with the average similarity to colonies in the most similar neighbouring cluster (see Fig. S2 in the Supplement). All were implemented with the function fviz_nbclust from the R-package factoextra (Kassambara \& Mundt 2017).

Finally, we assessed the strength of the final cluster structure for each algorithm using the silhouette width as described above. Values close to 0 indicate that a colony lies in between clusters and values around and above 0.5 indicate a 'reasonable' to 'strong' cluster structure (Kaufman \& Rousseeuw 2005). We also assessed the stability of the cluster structure using the average proportion of non-overlap, which measures the proportion of colonies that would be assigned to a different cluster if a random colony were to be removed from the data. Values close to zero suggest a stable structure. Both the silhouette widths and the proportion of non-overlap were calculated used the Rpackage clValid (Brock et al. 2008).

\subsection{Inferring causes of synchrony}

In order to investigate potential drivers of synchrony, we used matrix regression (see Lichstein 2007 and references therein). Here, the response variable is the matrix representing between-colony synchrony, and potential drivers are all also formulated as matrices. In our case, these alternative drivers included sandeel spatial structure, weather conditions and skua predation, as outlined in Section 1. In addition to this, we included an effect of distance, which could be a result of these drivers, but also other spatially autocorrelated drivers.

For sandeels, we assigned each colony to a sandeel sub-population, expecting colonies assigned to the same sub-population (1 in the matrix) to be more synchronous than colonies assigned to different subpopulations (0 in the matrix). Sub-population boundaries were based on current knowledge of sandeel spatial structure (Fig. 1a). Along the North Sea coast of the British mainland, there are 2 distinct sandeel sub-populations that are managed as separate ICES stock assessment areas (ICES 2017), delineated based on larval transport patterns (Christensen et al. 2008). This delineation is supported by both otolith microchemistry (Wright et al. 2018) and genetic structure (Jiménez-Mena et al. 2020). ICES has not considered the evidence for structuring north of mainland UK, but based on evidence from distribution (Wright 1996), larval transport modelling (Proc- 
tor et al. 1998) and otolith microchemistry (Gibb et al. 2017), we divided Orkney and Shetland into 2 separate sub-populations. We also assigned Handa Island (Colony 9) and North Sutor (Colony 16) to the Orkney sub-population, based on evidence from otolith microchemistry (Gibb et al. 2017) and recent larval drift simulations (Wright et al. 2019), respectively. It should be noted that as these sub-population boundaries are to a large degree based on larval transport they are not fixed, as transport varies between years, or absolute, meaning that aggregations near a boundary may be expected to display similar dynamics (Wright et al. 2019). Whether a colony pair belongs to the same sub-population or not is strongly related to the distance between them, and for this reason all sandeel models also included a distance effect to control for this. This also, to some extent, accounts for the fact that synchrony in sandeel dynamics also declines with distance, even within sandeel sub-populations (Wright et al. 2019).

Our knowledge of synchrony in skua predation pressure between colonies is poor. As a simple way to represent this driver, we defined an area in which kittiwake colonies are susceptible to predation by skuas based on knowledge of the distribution (Mitchell et al. 2004) and foraging distance (Wade et al. 2014) of skuas. This area included Handa Island (Colony 9) as well as colonies in Shetland and Orkney. Colony pairs that were both located within this area or both located outside this area were given a value of 1 in the matrix, whereas other pairs were given a value of zero. Again, these values will be confounded with distance, and so a distance effect was always included in the skua models. Similarly, while we do not know how the impact of skuas may be synchronised across space, it is reasonable to assume that it will decline with distance, and this will also be picked up by the distance effect.

As outlined in Section 1, weather (primarily rain and wind conditions) can also impact the breeding success of kittiwakes. In our analysis, weather was represented as a matrix of between-colony synchrony in daily total precipitation ( $\mathrm{mm}$ ) during the breeding season (May to August), measured as the Pearson correlation coefficient. This was based on data covering the full study period from the HadUK-Grid dataset, which provides data on a $1 \times 1 \mathrm{~km}$ grid, interpolated from the network of weather stations (Hollis et al. 2019, downloaded December 2019). We did not use wind speed as it is only available as monthly averages from this dataset, which is not at a fine enough scale to capture how similar conditions are for a given part of the kittiwake breeding cycle. However, the correlation between between-colony synchrony in monthly wind speed and between-colony synchrony in daily precipitation was high $(\mathrm{r}=0.85, \mathrm{p}<0.001)$, suggesting that this variable will be representative of similarity in weather conditions in general. Finally, as weather shows strong spatial autocorrelation, this may cause multicollinearity issues when included in the same model as the general distance effect. For this reason, we used the residuals from a smoothing spline of between-colony synchrony in precipitation as a function of between-colony distance to represent the effect of synchrony in weather conditions.

Both distance and weather were translated into similarities, so that the most similar colony pair were given a value of 1 , and the most dissimilar colony pair a value of 0 . Examining the residuals from the full linear model, it was clear that the effect of distance was not linear. This is common (e.g. Liebhold et al. 2004), and was also expected based on our findings (see Section 3.1.1). To deal with this, we modelled the effect of distance using a spline. We increased the degrees of freedom until the pattern in the residuals disappeared, stopping at 3 . We then created a set of candidate models as subsets of the full model (see Table 2). The model selection was based on the leave-n-out crossvalidation approach outlined by Walter et al. (2017), where models are ranked based on their predictive power. We used an $n$ of 4 (18\% of total number of colonies, similar to percentages reported in the supplementary material of Walter et al. 2017), where the predictive power is defined as the mean of the sum of squared errors between predicted and measured synchrony over all possible combinations of test sets of 4 colonies. In order to compare the support for the different models, we used a bootstrapping approach where colonies were resampled with replacement 250 times, model ranks were calculated for each resample and model weights were determined as the proportion of resamples where the model was ranked as the top model. Further, we calculated p-values with a permutation approach using the function MRM in the package ecodist (Goslee \& Urban 2007).

\section{RESULTS}

\subsection{Spatial patterns in synchrony}

\subsubsection{Effect of geographical distance on synchrony}

Between-colony synchrony ( $r_{\text {diff, }}$ correlation in the difference in breeding success between consecutive years) was high ( 0.75) for close-by colony pairs 
and declined with along-coast distance until around $300 \mathrm{~km}$, followed by a temporary increase centred around $600 \mathrm{~km}$ (Fig. 2), although the $99 \%$ confidence interval remained close to zero. The $99 \%$ confidence interval intersected with $r_{\text {diff }}=0$ at just over $200 \mathrm{~km}$, which can thus be considered to be the scale of spatial synchrony (Bjørnstad \& Falck 2001). A similar pattern was found when synchrony was measured as $r$ (correlation in untransformed time series of breeding success, Fig. S3 in the Supplement).

\subsubsection{Deviations from the distance-synchrony relationship}

When synchrony was measured as $r_{\text {diff, }}$ several colony pairs showed either stronger or weaker synchrony than expected based on distance (restricted to distances below which there was a clear relationship with synchrony, around 200 km, Fig. 2). On the Scottish east coast, many colony pairs showed strongerthan-expected synchrony, and this was also the case in Shetland (Fig. 1b). The 4 southernmost colonies in Orkney (Colonies 8, 13, 14 and 18) showed weakerthan-expected synchrony both with the more southerly colonies Handa Island (Colony 9) and North Sutor (Colony 16) as well as several colonies in Shetland. Unlike the other Orkney colonies, North Hill (Colony 15) showed stronger-than-expected synchrony with

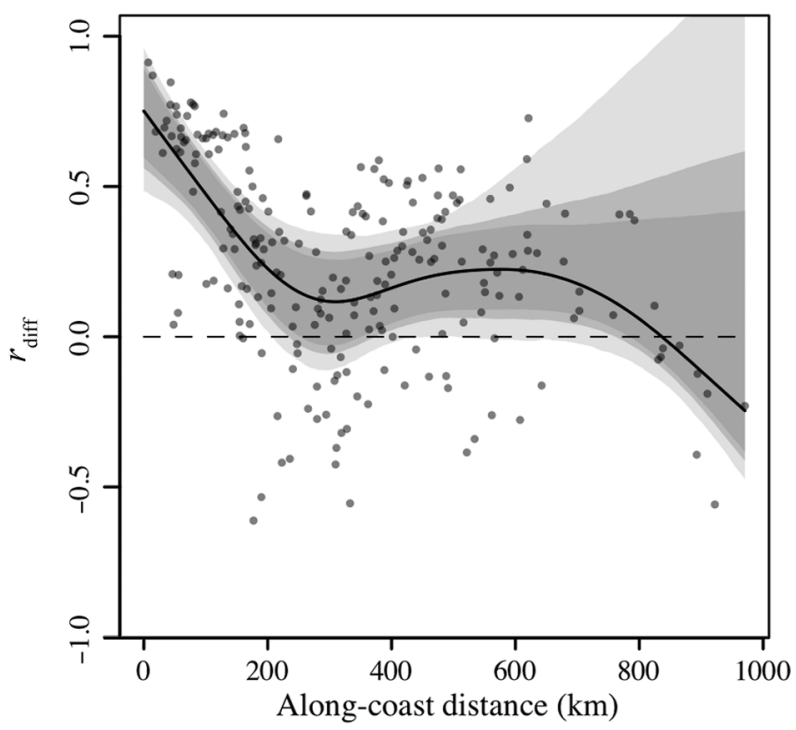

Fig. 2. Cubic smoothing spline fitted between the alongcoast distance and synchrony in inter-annual fluctuations $\left(r_{\text {diff }}\right)$ for each black-legged kittiwake colony pair (black line). Each point shows the $r_{\text {diff }}$ of a colony pair against the alongcoast distance between the 2 colonies. Dashed line: $r_{\text {diff }}=0$. Grey shading shows 99, 95 and $90 \%$ confidence intervals as estimated from boot-strapping several colonies in Shetland, and also weaker-thanexpected synchrony with the other Orkney colonies. There was a clear difference in the corresponding results when synchrony was measured as $r$ (Fig. S4a in the Supplement), in that the synchrony of the 4 southernmost colonies in Orkney with Handa Island and North Sutor were stronger-than-expected rather than weaker-than-expected.

\subsubsection{Cluster analysis}

We first clustered the colonies based on synchrony measured as $r_{\text {diff. }}$. While the optimal $k$ was slightly different for the different algorithms (Fig. S2), they all identified the same 3 core clusters (Fig. 1c), although a few colonies were assigned less consistently (see Table S2 in the Supplement for the final cluster structure for each algorithm). Starting from the north, the colonies in Shetland formed 1 cluster which was consistent across algorithms (Fig. 1c, yellow cluster), with Shetland colonies showing affinities of close to 50 or above with this cluster (Table 1). Outside Shetland, the English colonies Saltburn Cliffs (Colony 19) and Flamborough Head (Colony 5) as well as the Orkney colony North Hill (Colony 15) were consistently assigned to this cluster across algorithms. While all these colonies showed the highest affinity with this cluster, the affinity of North Hill was higher than those of the English colonies and similar to those of the Shetland colonies (Table 1). Apart from North Hill, all other colonies in Orkney were consistently assigned to the same cluster by all algorithms (Fig. 1c, black cluster). Going further south, both Handa Island (Colony 9) and North Sutor (Colony 16), were assigned inconsistently (Fig. 1c, grey), and showed similar affinities to all clusters (Table 1). The colonies on the Scottish east coast formed a consistent cluster (Fig. 1c, green), with affinities centred around 50 (Table 1). Finally, the southernmost colony of Lowestoft was assigned inconsistently (Fig. 1c, grey) but showed the strongest affinity with the Orkney cluster (Table 1). All algorithms had similar average silhouette widths of around 0.40 , indicating a weak to moderate cluster structure. Based on the calculated average proportion of non-overlap, clusters appeared to be moderately stable, where on average 29,26 and $38 \%$ of colonies would be re-assigned if a random colony were to be removed from the dataset for each of the 3 algorithms agnes, diana and pam, respectively.

When clustering was based on synchrony measured as $r$ rather than $r_{\text {diff, }}$ both Handa Island and 
Table 1. Results of the fuzzy clustering (fanny) showing the affinities (expressed as rounded percentages) of each colony to each of the 3 clusters in Fig. 1c (colours used in Fig. 1c are also indicated). Colony numbers correspond to numbers in Fig. 1a. The cluster with the highest affinity is shown in bold for each colony. We considered 3 clusters for the fuzzy clustering, based on the identification of 3 core clusters by all algorithms (see Section 3.1.3)

\begin{tabular}{|c|c|c|c|c|}
\hline \multirow{2}{*}{$\begin{array}{l}\text { Colony } \\
\text { number }\end{array}$} & \multirow{2}{*}{ Colony name } & \multicolumn{3}{|c|}{ Cluster } \\
\hline & & $\begin{array}{l}\text { Scottish east } \\
\text { coast (green) }\end{array}$ & $\begin{array}{l}\text { Orkney } \\
\text { (black) }\end{array}$ & $\begin{array}{c}\text { Shetland } \\
\text { (yellow) }\end{array}$ \\
\hline 1 & Buchan Ness & 48 & 31 & 20 \\
\hline 2 & Dunbar Coast & 47 & 28 & 25 \\
\hline 3 & Fair Isle & 20 & 21 & 59 \\
\hline 4 & Farne Islands & 44 & 31 & 25 \\
\hline 5 & $\begin{array}{l}\text { Flamborough } \\
\text { Head }\end{array}$ & 31 & 34 & 35 \\
\hline 6 & Foula & 24 & 25 & 51 \\
\hline 7 & Fowlsheugh & 51 & 26 & 23 \\
\hline 8 & Gultak & 27 & 49 & 23 \\
\hline 9 & Handa Island & 36 & 29 & 34 \\
\hline 10 & Hermaness & 23 & 28 & 49 \\
\hline 11 & Isle of May & 55 & 24 & 21 \\
\hline 12 & Lowestoft & 29 & 42 & 29 \\
\hline 13 & $\begin{array}{l}\text { Marwick } \\
\text { Head }\end{array}$ & 30 & 47 & 23 \\
\hline 14 & Mull Head & 27 & 52 & 22 \\
\hline 15 & North Hill & 22 & 25 & 53 \\
\hline 16 & North Sutor & 31 & 40 & 29 \\
\hline 17 & Noss & 21 & 23 & 56 \\
\hline 18 & Row Head & 26 & 49 & 25 \\
\hline 19 & Saltburn Cliffs & 32 & 32 & 37 \\
\hline 20 & St Abb's Head & 52 & 26 & 22 \\
\hline 21 & $\begin{array}{l}\text { Sumburgh } \\
\text { Head }\end{array}$ & 25 & 28 & 47 \\
\hline 22 & Whale Wick & 25 & 21 & 54 \\
\hline
\end{tabular}

North Sutor were consistently clustered with Orkney, and this was also the case for the 2 southernmost English colonies, Saltburn Cliffs and Lowestoft (Fig. $\mathrm{S} 4 \mathrm{~b})$. Looking at the time series of breeding success for the different clusters (Fig. 3), the difference between using $r$ and $r_{\text {diff }}$ becomes clear. While Handa Island and North Sutor do not seem to show similar inter-annual fluctuations to Orkney, they show a similar drop in breeding success in the early 2000s, and as such show correlated long-term patterns. Fig. 3 also illustrates how colonies within each core cluster generally show clear synchrony in their fluctuations.

\subsection{Inferring causes of synchrony}

The model with the highest weight when synchrony was measured as $r_{\text {diff }}$ only included an effect of distance (Table 2). The model with the highest weight when synchrony was measured as $r$ also included distance, but contained an effect of sandeel sub-population as well, where colony pairs assigned to the same sandeel sub-population showed a synchrony of 0.24 units higher than colony pairs assigned to different sandeel sub-populations after accounting for the effect of distance $(p=0.003)$. The model weights indicated that there was no support for skua predation or weather conditions driving the observed synchrony patterns, regardless of whether synchrony was measured as $r$ or $r_{\text {diff }}$.

\section{DISCUSSION}

In this study, we found clear evidence of geographical patterns in the synchrony of breeding success in our examined British kittiwake colonies. As expected, the distance between colonies was an important determinant of between-colony synchrony. However, some colony pairs showed stronger or weaker synchrony than expected based on distance and this was also reflected in the configuration of spatially coherent clusters of colonies with synchronous breeding success. There was some evidence that the spatial structure of the kittiwakes' sandeel prey played a role in generating the observed patterns, but this depended on how synchrony was measured. As such, the results lend some support to the hypothesis developed by Furness et al. (1996) and Frederiksen et al. (2005) that spatial synchrony in kittiwake breeding success in the UK is driven by the spatial structure of sandeel populations, but also show that the story is potentially more complex. On a broader scale, our findings show that examining spatial patterns in synchrony can provide useful information on potential demographic drivers and also highlight that different stories can emerge depending on how synchrony is measured.

The negative effect of distance on synchrony, with synchrony declining up to a distance of just over $200 \mathrm{~km}$, aligns with previous studies of spatial sychrony (Liebhold et al. 2004). However, patterns were less clear beyond this initial decline. Centred at around $600 \mathrm{~km}$, there was a temporary increase, and although the confidence intervals remained close to zero, it is possible that this weak positive synchrony at long distances reflects large-scale drivers that may generate synchrony in kittiwake breeding success, such as carry-over effects from shared wintering areas (see Frederiksen et al. 2012). Centred at around $300 \mathrm{~km}$, there are multiple negative correlations. This dip may not necessarily have any biologi- 
a) Shetland

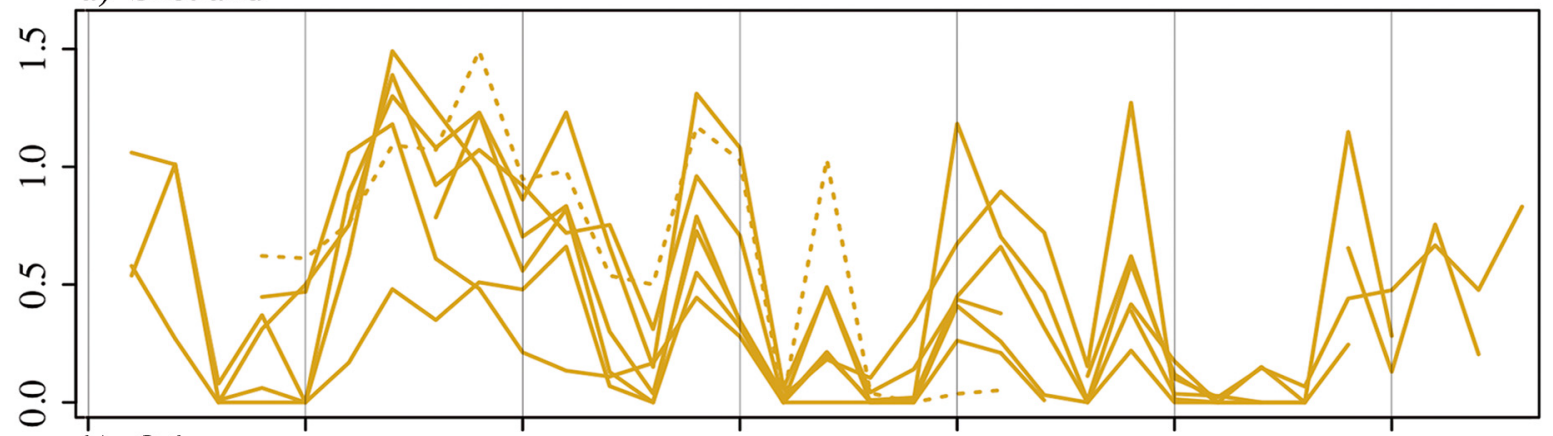

b) Orkney

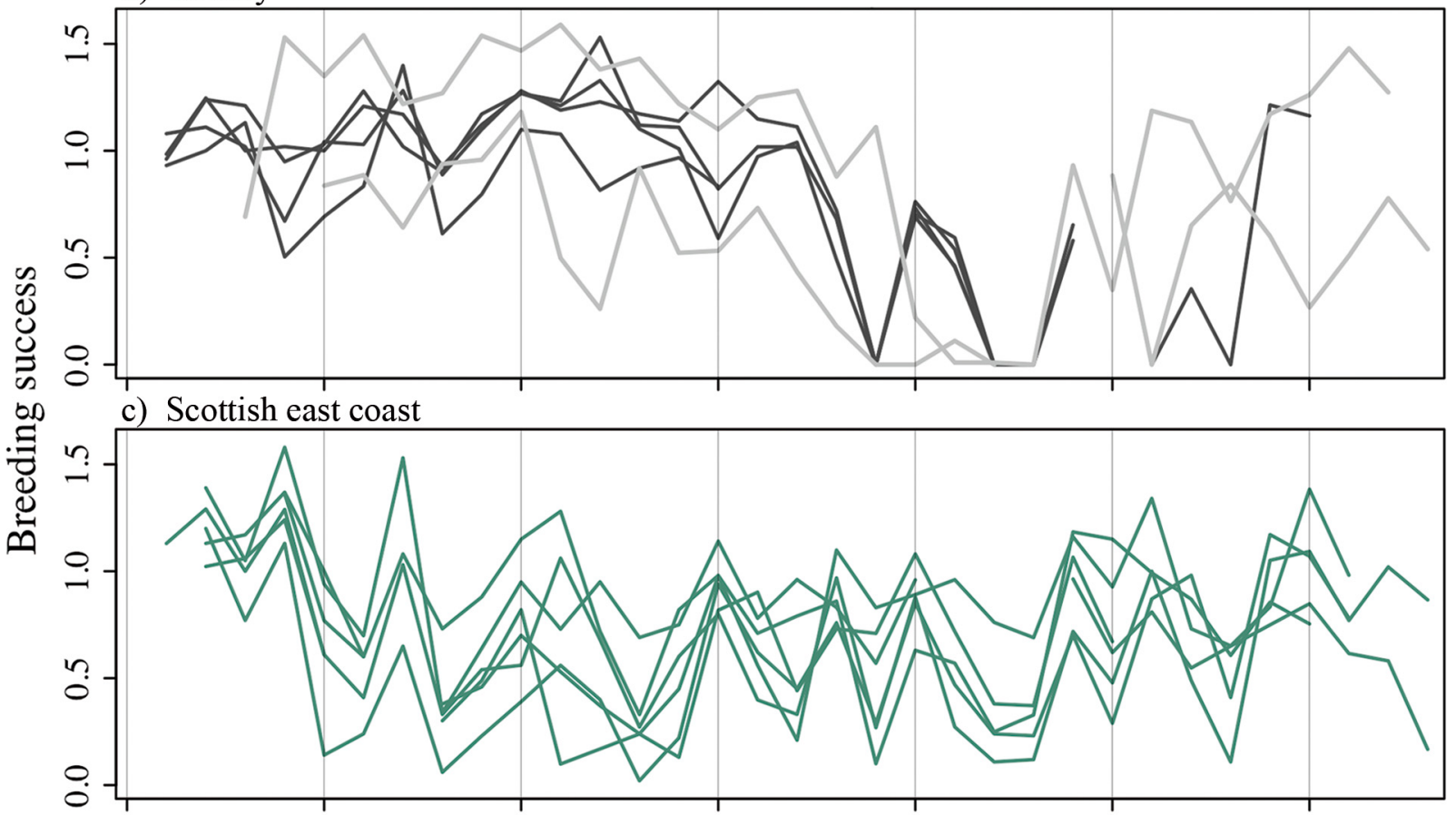

d) East England

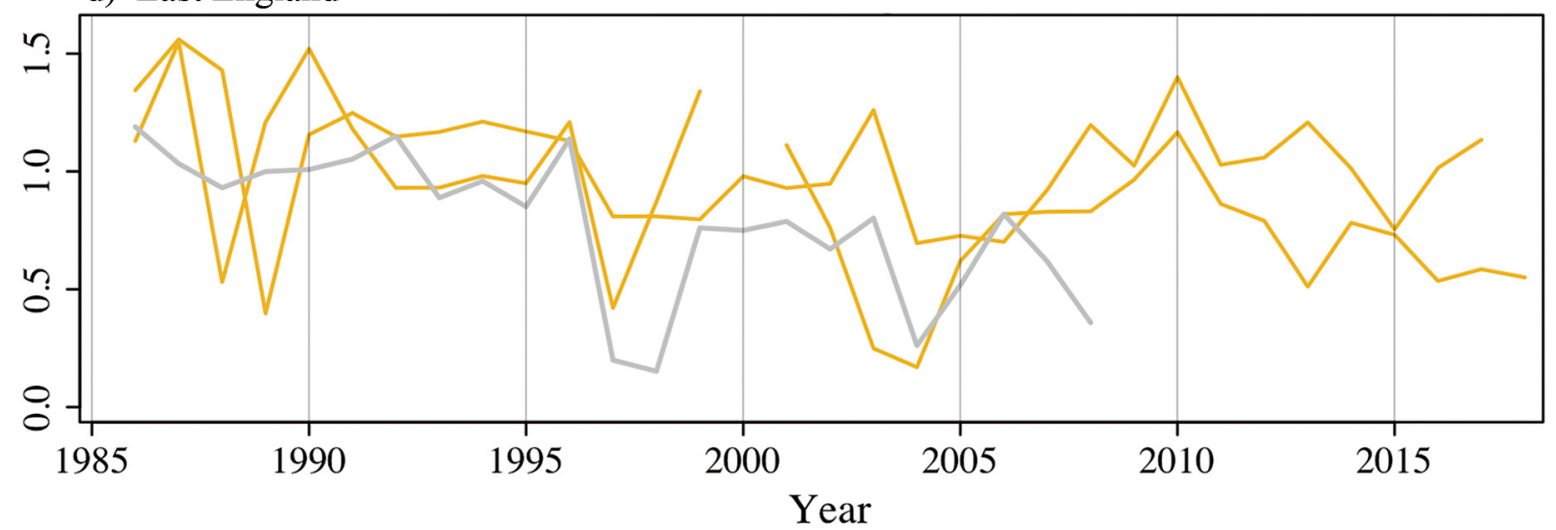

Fig. 3. Time series of black-legged kittiwake breeding success. (a) All colonies in Shetland assigned to the yellow Shetland cluster (see Fig. 1c), as well as the Orkney colony North Hill (Colony 15, dashed line) that was also assigned to this cluster. (b) All colonies in Orkney assigned to the black Orkney cluster (see Fig. 1c), as well as (grey) the colonies Handa Island (Colony 9) and North Sutor (Colony 16). (c) All colonies included in the green Scottish east coast cluster (see Fig. 1c). Note that this also includes the English colony Farne Islands (Colony 4). (d) Rest of the English colonies. Yellow: Flamborough Head (Colony 5) and Saltburn Cliffs (Colony 19), which were assigned to the yellow Shetland cluster; grey: Lowestoft (Colony 12), which was assigned to different clusters by the different algorithms. The cluster structure is based on synchrony measured as the synchrony in inter-annual fluctuation $\left(r_{\text {diff }}\right)$ 
Table 2. Model weights for all candidate models from the matrix regression. Model weights were calculated as the proportion of times the given model was ranked as the top model based on 250 resamples. Weights are given for models where synchrony was measured as synchrony in inter-annual fluctuations $\left(r_{\text {diff }}\right)$ and models where it was measured as synchrony in both inter-annual fluctuations and long-term trends $(r)$. The largest model weight for each synchrony measure is indicated in bold

\begin{tabular}{|lcc|}
\hline \multirow{2}{*}{ Explanatory variables } & \multicolumn{2}{c|}{ Model weights } \\
& $r_{\text {diff }}$ & $r$ \\
\hline distance + weather + skuas + sandeels & 2 & 2.4 \\
distance + weather + skuas & 6.8 & 3.2 \\
distance + weather + sandeels & 4.8 & 16.4 \\
distance + sandeels + skuas & 2.8 & 5.6 \\
distance + weather & 25.2 & 5.6 \\
distance + sandeels & 10 & $\mathbf{4 1 . 6}$ \\
distance + skuas & 7.6 & 6.8 \\
distance & $\mathbf{3 2 . 4}$ & 15.6 \\
weather & 1.6 & 0.4 \\
Null & 6.8 & 2.4 \\
\hline
\end{tabular}

cal meaning, but may instead be the result of multiple negative correlations between colonies on the Scottish east coast and colonies in Shetland and Orkney, with many colony-pairs being separated by similar distances. Even at shorter distances, the large residuals indicated that the spatial pattern in synchrony was more complex than a simple decline with distance. The distribution of colony pairs showing weaker-than-expected or stronger-than-expected synchrony showed a clear spatial pattern, and this was also reflected in the spatial configuration of clusters showing synchronous breeding success. The geographical structure, with Shetland, southern Orkney and the Scottish east coast each forming consistent clusters, was similar but more spatially coherent than that found in Furness et al. (1996) and Frederiksen et al. (2005), and also aligned with the strong correlations on the Scottish east coast observed by Harris \& Wanless (1997).

There was some evidence that this geographical structure was driven by sandeel spatial structure, where the 3 identified core clusters were situated in separate sandeel sub-population regions. In particular, the sandeel sub-population on the Scottish east coast can be clearly distinguished from other subpopulations (Wright et al. 2018, 2019, Jiménez Mena et al. 2020), and this was reflected in a strong cluster of colonies with synchronous breeding success. The information on sandeel spatial structure is less complete in Shetland and Orkney, and patterns of kittiwake breeding success synchrony were also less clear here. For example, North Hill (Colony 15) in the north of Orkney consistently clustered with the Shetland colonies (Fig. 1c) even though we assigned this colony to the Orkney sandeel sub-population. This could reflect our incomplete knowledge of sub-population borders, but may also reflect the ability of kittiwakes to cross these borders, where Shetland sandeel grounds are within reach for North Hill kittiwakes. Interestingly, when examining the support for different drivers of synchrony, sandeel sub-population structure was included in the most well-supported model when synchrony was measured as $r$ (reflecting both correlated long-term signals and correlated inter-annual differences) but not when synchrony was measured as $r_{\text {diff }}$ (reflecting correlated inter-annual differences only). This suggests that synchrony in long-term patterns align better with sandeel spatial structure than synchrony in interannual fluctuations. To a large extent, the difference was likely driven by Handa Island (Colony 9) and North Sutor (Colony 16) showing similar long-term patterns to Orkney, but not similar inter-annual fluctuations. In particular, a synchronised drop in breeding success in the 2000s could be seen in all colonies assigned to the Orkney sandeel sub-population. It is possible that this drop was the result of a collapse of the sandeel sub-population around Orkney, which includes an extensive spawning ground (Lynam et al. 2013). This is further supported by a concurrent drop in the breeding success of other sandeel-eating seabirds in Orkney (JNCC 2016) and could potentially be linked to large-scale shifts in environmental conditions occurring around this time impacting sandeel recruitment (see Alvarez-Fernandez et al. 2012). This shows how looking at different metrics of synchrony can be useful, where synchrony in long-term patterns can potentially point to mutual responses to large-scale processes, such as the potential collapse of a sandeel spawning stock in this case. However, caution should be observed when inferring drivers from similar long-term patterns, as they could be the result of separate processes.

Some other features of the data also provide circumstantial evidence supporting sandeel dynamics as a governing force. The scale of synchrony, just over $200 \mathrm{~km}$, is similar to the scale of sandeel synchrony (Wright et al. 2019), where similar scales of synchrony in the hypothesised driver and the target population can be used to infer a causal relationship (Bjørnstad \& Falck 2001). However, it should be noted that different mechanisms can generate similar patterns of distance-decay (Abbott 2007) and that between-colony distance is not exactly equal to the distance between the sandeel grounds in which the 
kittiwakes may be feeding, as they may forage in several directions from the colony (e.g. Robertson et al. 2014, Christensen-Dalsgaard et al. 2018a) and at various distances (Thaxter et al. 2012), with differences potentially exacerbated by colonies generally showing segregated foraging areas (e.g. Bolton et al. 2019). In addition to this, in many colonies, in particular in Shetland and on the Scottish east coast, breeding success fluctuated on a biannual time-scale (see Fig. 3), which fits with similar biannual fluctuations in sandeel recruitment (e.g. Arnott \& Ruxton 2002, van Deurs et al. 2009) and thus provides additional support for sandeels as a potential driver of synchrony. Taking all the evidence together, it seems as if the independent and disparate dynamics of sandeel sub-populations filter up to the level of kittiwakes. The role played by sandeels is likely larger further north where sandeel is a more important prey item. In Shetland and Orkney, there is an almost total lack of alternative prey for kittiwakes (e.g. Hamer et al. 1993, Furness \& Tasker 2000), but the importance appears to decline the further south along the coast you go (Furness \& Tasker 2000, Carter 2014, Wanless et al. 2018).

While the support for sandeel as the main driver was not conclusive, there was even less support for the alternative drivers we examined: weather conditions and skua predation. When it comes to the role of weather conditions, we cannot rule out that the distance effect is to some extent the result of synchrony in weather conditions. However, the lack of support for including additional variation in weather synchrony suggests that it is not a major driver. One minor caveat is that while we used data on a highly resolved spatial scale, we did not take into account that the direction and exposure of a colony could to some extent determine the impact of weather conditions (Newell et al. 2015). Similarly, there was no evidence suggesting that skua predation was a key driver of the observed synchrony patterns. It should be noted that we could only capture skua predation as a driving force in a simplistic way and we can thus not exclude it as a driver of synchrony, at least locally. Further, the vulnerability of kittiwake colonies to skuas will depend to a large extent on how accessible they are (Heubeck 2002), and this was not accounted for in this study. However, the strong synchrony on the Scottish east coast, where skua predation pressure is low, clearly shows that skua predation cannot be the only driver of synchrony.

The spatial independence in breeding success we found could have important consequences for the long-term trajectory of the UK kittiwake population as a whole, as uncorrelated fluctuations in population dynamics tend to have a positive impact on longterm persistence (Heino et al. 1997, Palmqvist \& Lundberg 1998, Engen et al. 2002). It is clear that the different clusters have shown quite different patterns in breeding success over time (Figs. 1a \& 3 ) and, as expected from the fact that breeding success is an important driver of changes in colony sizes in the UK (Coulson 2017), this spatial variation in breeding success is mirrored by variation in colony size trajectories. In Shetland, breeding success has been variable but often low, with frequent cluster-wide breeding failures, and along these lines, Shetland colonies have experienced substantial declines since the late 1980s (see JNCC 2016). In the Orkney cluster, breeding success was generally high until the early 2000 s before dropping and becoming more variable, and this also coincided with a steep drop in colony sizes (see JNCC 2016). On the Scottish east coast, breeding success has generally been quite low and variable, but the cluster has rarely showed cluster-wide failure. While colony sizes have declined here as well, the declines have been more variable and not as steep as further north (see JNCC 2016). The English colonies have generally maintained relatively high levels of breeding success and as a result, declines in colony size have been slower or absent (see JNCC 2016). As such, it is clear that there are spatial patterns both in synchrony and in long-term trajectories.

If the spatial patterns in breeding success that we have identified are driven by sandeel spatial structure, this would support the more general hypothesis that trophic interactions with prey displaying spatial synchrony can drive spatial synchrony in predators in some systems (see Liebhold et al. 2004). This is in line with previous theoretical studies finding that synchrony can propagate through food webs (Ripa \& Ranta 2007), as well as empirical studies finding that synchrony in predators can be driven by synchrony in their prey (e.g. Haynes et al. 2009), even to the extent that studying the patterns of synchrony in predators can tell us something about a less wellstudied prey population (e.g. Fay et al. 2020). In particular, interactions with prey as a driver of synchrony is likely to be expected where bottom-up effects are strong, such as in our case, where breeding success and food conditions are closely linked in kittiwakes (e.g. Gill \& Hatch 2002) and bottom-up effects have been identified as a strong governing force (Frederiksen et al. 2006). In addition, the sedentary behaviour and thus relatively permanent and fine-scale spatial structure of the sandeel popu- 
lation may mean that, in this case, the prey spatial structure plays an unusually large role in generating synchrony. Still, similar conditions may be found in other systems. For example, a closely related species of the lesser sandeel, the Pacific sandeel Ammodytes hexapterus, is an important prey for several species of seabirds in a large area of the north Pacific (e.g. Litzow et al. 2000, Hedd et al. 2006), and being very similar to A. marinus, it likely also displays clear spatial structure, which seems to filter up to the level of seabirds (Litzow et al. 2000) and is likely to impact their breeding success (see Hedd et al. 2006). Other important forage fish species used by seabirds also tend to show increasingly independent dynamics over space (e.g. Östman et al. 2017, Marquez et al. 2019), which likely impacts spatial patterns of breeding success and long-term population trajectories of seabirds. Our work adds to other seabird studies (e.g. Descamps et al. 2013, O'Hanlon \& Nager 2018) showing that spatial patterns of population synchrony can provide useful information on ecosystem drivers of population dynamics and over which spatial scale they are acting.

Acknowledgements. We are very grateful to everyone who has contributed data to the Seabird Monitoring Programme, coordinated by the JNCC, and the Isle of May dataset. We are also thankful to Alan MacDonald and 2 anonymous reviewers for very constructive comments which improved the manuscript greatly, as well as to Thomas Régnier for useful input on the cluster analysis. The study was funded by a doctoral fellowship from the Marine Alliance for Science and Technology Scotland (MASTS), in partnership with University of Strathclyde and University of Glasgow, as well as by the Natural Environment Research Council and the Department for Environment, Food and Rural Affairs (grant number NE/L003090/1. Marine Ecosystems Research Programme).

\section{LITERATURE CITED}

Abbott KC (2007) Does the pattern of population synchrony through space reveal if the Moran effect is acting? Oikos 116:903-912

Alvarez-Fernandez S, Lindeboom H, Meesters E (2012) Temporal changes in plankton of the North Sea: community shifts and environmental drivers. Mar Ecol Prog Ser 462:21-38

Alvestad RJ (2015) Effects of climate on chick growth in the black-legged kittiwake (Rissa tridactyla). MSc thesis, Norwegian University of Science and Technology, Trondheim

Arnott SA, Ruxton GD (2002) Sandeel recruitment in the North Sea: demographic, climatic and trophic effects. Mar Ecol Prog Ser 238:199-210

BirdLife International (2018) Rissa tridactyla. The IUCN Red List of Threatened Species 2018: e.T22694497A13255 6442
Bjørnstad ON (2019) ncf: spatial covariance functions. $\mathrm{R}$ package version 1.2-8. https://CRAN.R-project.org/ package $=$ ncf

* Bjørnstad ON, Falck W (2001) Nonparametric spatial covariance functions: estimation and testing. Environ Ecol Stat 8:53-70

* Bolton M, Conolly G, Carroll M, Wakefield ED, Caldow R (2019) A review of the occurrence of inter-colony segregation of seabird foraging areas and the implications for marine environmental impact assessment. Ibis 161: 241-259

* Brock G, Pihur V, Datta S, Datta S (2008) clValid: an R package for cluster validation. J Stat Softw 25:1-22. https:// CRAN.R-project.org/package $=$ clValid

*Bonaccorsi JP, Elkinton JS, Evans SR, Liebhold AM (2001) Measuring and testing for spatial synchrony. Ecology 82: 1668-1679

Carter C (2014) The success of a small East Anglian colony of kittiwakes may be due to a diet supplemented by clupeids. Seabird Group Newsl 126:8-10

* Christensen A, Jensen H, Mosegaard H, St. John M, Schrum C (2008) Sandeel (Ammodytes marinus) larval transport patterns in the North Sea from an individual-based hydrodynamic egg and larval model. Can J Fish Aquat Sci 65:1498-1511

Christensen-Dalsgaard S, May R, Lorentsen SH (2018a) Taking a trip to the shelf: Behavioral decisions are mediated by the proximity to foraging habitats in the blacklegged kittiwake. Ecol Evol 8:866-878

Christensen-Dalsgaard S, May RF, Barrett RT, Langset M, Sandercock BK, Lorentsen SH (2018b) Prevailing weather conditions and diet composition affect chick growth and survival in the black-legged kittiwake. Mar Ecol Prog Ser 604:237-249

* Collins PM, Green JA, Dodd S, Shaw PJA, Halsey LG (2014) Predation of black-legged kittiwake chicks Rissa tridactyla by a peregrine falcon Falco peregrinus: insights from time-lapse cameras. Wilson J Ornithol 126:158-161

Coulson JC (2017) Productivity of the black-legged kittiwake Rissa tridactyla required to maintain numbers. Bird Study 64:84-89

* Descamps S, Strøm H, Steen H (2013) Decline of an arctic top predator: synchrony in colony size fluctuations risk of extinction and the subpolar gyre. Oecologia 173: 1271-1282

* Descamps S, Anker-Nilssen T, Barrett RT, Irons DB and others (2017) Circumpolar dynamics of a marine top-predator track ocean warming rates. Glob Chang Biol 23: 3770-3780

*Engen S, Lande R, Sæether BE (2002) The spatial scale of population fluctuations and quasi-extinction risk. Am Nat 160:439-451

* Fay R, Michler S, Laesser J, Jeanmonod J, Schaub M (2020) Large-scale vole population synchrony in central Europe as revealed by kestrel breeding performance. Front Ecol Evol 7:512

Frederiksen M, Wright PJ, Harris MP, Mavor RA, Heubeck M, Wanless S (2005) Regional patterns of kittiwake Rissa tridactyla breeding success are related to variability in sandeel recruitment. Mar Ecol Prog Ser 300:201-211

* Frederiksen M, Edwards M, Richardson AJ, Halliday NC, Wanless S (2006) From plankton to top predators: bottom-up control of a marine food web across four trophic levels. J Anim Ecol 75:1259-1268

Frederiksen M, Furness RW, Wanless S (2007) Regional vari- 
ation in the role of bottom-up and top-down processes in controlling sandeel abundance in the North Sea. Mar Ecol Prog Ser 337:279-286

Frederiksen M, Moe B, Daunt F, Phillips RA and others (2012) Multicolony tracking reveals the winter distribution of a pelagic seabird on an ocean basin scale. Divers Distrib 18:530-542

Furness RW, Tasker ML (2000) Seabird-fishery interactions: quantifying the sensitivity of seabirds to reductions in sandeel abundance, and identification of key areas for sensitive seabirds in the North Sea. Mar Ecol Prog Ser 202:253-264

Furness RW, Greenstreet SPR, Walsh PM (1996) Spatial and temporal variability in the breeding success of seabirds around the British Isles: Evidence for distinct sandeel stocks? ICES Coop Res Rep 216:63-65

Galbraith H (1983) The diet and feeding ecology of breeding kittiwakes Rissa tridactyla. Bird Study 30:109-120

Gibb FM, Régnier T, Donald K, Wright PJ (2017) Connectivity in the early life history of sandeel inferred from otolith microchemistry. J Sea Res 119:8-16

* Gill VA, Hatch SA (2002) Components of productivity in black-legged kittiwakes Rissa tridactyla: response to supplemental feeding. J Avian Biol 33:113-126

Goslee SC, Urban DL (2007) The ecodist package for dissimilarity-based analysis of ecological data. J Stat Softw 22: $1-19$

* Grenfell BT, Wilson K, Finkenstädt BF, Coulson TN and others (1998) Noise and determinism in synchronized sheep dynamics. Nature 394:674-677

Grøtan V, Sæther BE, Engen S, Solberg EJ and others (2005) Climate causes large scale spatial synchrony in population fluctuations of a temperate herbivore. Ecology 86: 1472-1482

* Hamer KC, Monaghan P, Uttley JD, Walton P, Burns MD (1993) The influence of food supply on the breeding ecology of kittiwakes Rissa tridactyla in Shetland. Ibis 135: 255-263

Harris MP, Wanless S (1997) Breeding success, diet, and brood neglect in the kittiwake (Rissa tridactyla) over an 11-year period. ICES J Mar Sci 54:615-623

* Haynes KJ, Liebhold AM, Fearer TM, Wang G, Norman GW, Johnson DM (2009) Spatial synchrony propagates through a forest food web via consumer-resource interactions. Ecology 90:2974-2983

Hedd A, Bertram DF, Ryder JL, Jones IL (2006) Effects of interdecadal climate variability on marine trophic interactions: rhinoceros auklets and their fish prey. Mar Ecol Prog Ser 309:263-278

*Heino M, Kaitala V, Ranta E, Lindström J (1997) Synchronous dynamics and rates of extinction in spatially structured populations. Proc Biol Sci 264:481-486

Heubeck M (2002) The decline of Shetland's kittiwake population. Br Birds 95:118-122

Hijmans RJ (2018) raster: geographic data analysis and modeling. R package version 28-4. https://CRAN.R-project.org/package=raster

Holland GJ, Greenstreet SPR, Gibb IM, Fraser HM, Robertson MR (2005) Identifying sandeel Ammodytes marinus sediment habitat preferences in the marine environment. Mar Ecol Prog Ser 303:269-282

Hollis D, McCarthy M, Kendon M, Legg T, Simpson I (2019) HadUK-Grid-a new UK dataset of gridded climate observations. Geosci Data J 6:151-159

ICES (2017) Report of the Benchmark Workshop on Sandeel
(WKSand 2016), 31 October to 4 November 2016, Bergen. ICES CM 2016/ACOM:33. ICES, Copenhagen

Ims RA, Andreassen HP (2000) Spatial synchronization of vole population dynamics by predatory birds. Nature 408:194-196

Jensen H, Rindorf A, Wright PJ, Mosegaard H (2011) Inferring the location and scale of mixing between habitat areas of lesser sandeel through information from the fishery. ICES J Mar Sci 68:43-51

Jiménez-Mena B, Le Moan A, Christensen A, van Deurs M, Mosegaard H, Hemmer Hansen J, Bekkevold D (2020) Weak genetic structure despite strong genomic signal in lesser sandeel in the North Sea. Evol Appl 13:376-387

JNCC (Joint Nature Conservation Committee) (2016) Seabird population trends and causes of change: 1986-2015 report. Joint Nature Conservation Committee. Updated September 2016. https://jncc.gov.uk/our-work/seabirdpopulation-trends-and-causes-of-change-1986-2015report-category/

Kassambara A, Mundt F (2017) factoextra: extract and visualize the results of multivariate data analyses. R package version 105. https://CRAN.R-project.org/package=facto extra

Kaufman L, Rousseeuw PJ (2005) Finding groups in data: an introduction to cluster analysis. John Wiley, Hoboken, NJ

KLichstein JW (2007) Multiple regression on distance matrices: a multivariate spatial analysis tool. Plant Ecol 188: $117-131$

* Liebhold A, Koenig WD, Bjørnstad ON (2004) Spatial synchrony in population dynamics. Annu Rev Ecol Evol Syst 35:467-490

K Liebhold AM, Johnson DM, Bjørnstad ON (2006) Geographic variation synchronizing effect of dispersal and regional stochasticity. Popul Ecol 48:131-138

KLitzow MA, Piatt JF, Abookire AA, Prichard AK, Robards MD (2000) Monitoring temporal and spatial variability in sandeel (Ammodytes hexapterus) abundance with pigeon guillemot (Cepphus columba) diets. ICES J Mar Sci 57:976-986

₹ Lynam CP, Halliday NC, Höffle H, Wright PJ, van Damme CJG, Edwards M, Pitois SG (2013) Spatial patterns and trends in abundance of larval sandeels in the North Sea: 1950-2005. ICES J Mar Sci 70:540-553

MacDonald A, Heath MR, Edwards M, Furness RW and others (2015) Climate-driven trophic cascades affecting seabirds around the British Isles. Oceanogr Mar Biol Annu Rev 53:55-79

MacDonald A, Speirs DC, Greenstreet SPR, Heath MR (2018) Exploring the influence of food and temperature on North Sea sandeels using a new dynamic energy budget model. Front Mar Sci 5:339

Maechler M, Rousseeuw P, Struyf A, Hubert M, Hornik K (2018) cluster: cluster analysis basics and extensions. R package version 207-1. https://CRAN.R-project.org/ package $=$ cluster

Marquez JF, Lee AM, Aanes S, Engen S, Herfindal I, Salthaug A, Sæther BE (2019) Spatial scaling of population synchrony in marine fish depends on their life history. Ecol Lett 22:1787-1796

Mitchell PI, Newton SF, Ratcliffe N, Dunn TE (eds) (2004) Seabird populations of Britain and Ireland: results of the Seabird 2000 census (1998-2002). T \& AD Poyser, London

Moran PAP (1953) The statistical analysis of the Canadian lynx cycle. Aust J Zool 1:291-298 
Newell M, Wanless S, Harris MP, Daunt F (2015) Effects of an extreme weather event on seabird breeding success at a North Sea colony. Mar Ecol Prog Ser 532:257-268

Newell M, Harris MP, Wanless S, Burthe S, Bogdanova M, Gunn CM, Daunt F (2016) The Isle of May longterm study (IMLOTS) seabird annual breeding success 1982-2016. NERC Environmental Information Data Centre

* O'Hanlon NJ, Nager RG (2018) Identifying habitat-driven spatial variation in colony size of herring gulls Larus argentatus. Bird Study 65:306-316

Östman Ö, Olsson J, Dannewitz J, Palm S, Florin AB (2017) Inferring spatial structure from population genetics and spatial synchrony in demography of Baltic Sea fishes: implications for management. Fish Fish 18:324-339

Palmqvist E, Lundberg P (1998) Population extinctions in correlated environments. Oikos 83:359-367

Post E, Forchhammer MC (2002) Synchronization of animal population dynamics by large-scale climate. Nature 420 : 168-171

Proctor R, Wright PJ, Everitt A (1998) Modelling the transport of larval sandeels on the north-west European shelf. Fish Oceanogr 7:347-354

Pyper BJ, Peterman RM (1998) Comparison of methods to account for autocorrelation in correlation analyses of fish data. Can J Fish Aquat Sci 55:2127-2140

R Core Team (2018) R: a language and environment for statistical computing. R Foundation for Statistical Computing, Vienna

Régnier T, Gibb FM, Wright PJ (2017) Importance of trophic mismatch in a winter-hatching species: evidence from lesser sandeel. Mar Ecol Prog Ser 567:185-197

Rindorf A, Wright PJ, Jensen H, Maar M (2016) Spatial differences in growth of lesser sandeel in the North Sea. J Exp Mar Biol Ecol 479:9-19

Ripa J, Ranta E (2007) Biological filtering of correlated environments: towards a generalised Moran theorem. Oikos 116:783-792

Robertson GS, Bolton M, Grecian WJ, Monaghan P (2014) Inter- and intra-year variation in foraging areas of breeding kittiwakes (Rissa tridactyla). Mar Biol 161: 1973-1986

Sandvik H, Reiertsen TK, Erikstad KE, Anker-Nilssen T and others (2014) The decline of Norwegian kittiwake populations: modelling the role of ocean warming. Clim Res 60:91-102

Schwartz MK, Mills LS, McKelvey KS, Ruggiero LF, Allendorf FW (2002) DNA reveals high dispersal synchronizing the population dynamics of Canada lynx. Nature 415: 520-522

South A (2011) rworldmap: a new R package for mapping global data. R J 3:35-43. https://CRAN.R-project.org/ package $=$ rworldmap

Stenseth NC, Mysterud A, Ottersen G, Hurrell JW, Chan KS,

Editorial responsibility: Kyle Elliott,

Sainte-Anne-de-Bellevue, Québec, Canada
Lima M (2002) Ecological effects of climate fluctuations. Science 297:1292-1296

* Sutcliffe OL, Thomas CD, Moss D (1996) Spatial synchrony and asynchrony in butterfly population dynamics. J Anim Ecol 65:85-95

* Thaxter CB, Lascelles B, Sugar K, Cook ASCP and others (2012) Seabird foraging ranges as a preliminary tool for identifying candidate Marine Protected Areas. Biol Conserv 156:53-61

*van Deurs M, van Hal R, Tomczak MT, Jónasdóttir SH, Dolmer P (2009) Recruitment of lesser sandeel Ammodytes marinus in relation to density dependence and zooplankton composition. Mar Ecol Prog Ser 381:249-258

*Votier SC, Bearhop S, Ratcliffe N, Phillips RA, Furness RW (2004) Predation by great skuas at a large Shetland seabird colony. J Appl Ecol 41:1117-1128

*Wade HM, Masden EA, Jackson AC, Thaxter CB, Burton NHK, Bouten W, Furness RW (2014) Great skua (Stercorarius skua) movements at sea in relation to marine renewable energy developments. Mar Environ Res 101: 69-80

Walsh PM, Halley DJ, Harris MP, del Nevo A, Sim IMW, Tasker ML (1995) Seabird monitoring handbook for Britain and Ireland: a compilation of methods for survey and monitoring of breeding birds. Joint Nature Conservation Committee, Peterborough

*Walter JA, Sheppard LW, Anderson TL, Kastens JH, Bjørnstad ON, Liebhold AM, Reuman DC (2017) The geography of spatial synchrony. Ecol Lett 20:801-814

*Wanless S, Harris MP, Newell MA, Speakman JR, Daunt F (2018) Community-wide decline in the occurrence of lesser sandeels Ammodytes marinus in seabird chick diets at a North Sea colony. Mar Ecol Prog Ser 600: 193-206

*Ward JH Jr (1963) Hierarchical grouping to optimize an objective function. J Am Stat Assoc 58:236-244

Wright PJ (1996) Is there a conflict between sandeel fisheries and seabirds? A case study at Shetland. In: Greenstreet SPR, Tasker M (eds) Aquatic predators and their prey. Fishing News Books, Oxford, p 154-165

Wright PJ, Jensen H, Tuck I (2000) The influence of sediment type on the distribution of the lesser sandeel, Ammodytes marinus. J Sea Res 44:243-256

*Wright PJ, Orpwood JE, Scott BE (2017) Impact of rising temperature on reproductive investment in a capital breeder: the lesser sandeel. J Exp Mar Biol Ecol 486: 52-58

*Wright PJ, Régnier T, Gibb FM, Augley J, Devalla S (2018) Identifying stock structuring in the sandeel, Ammodytes marinus, from otolith microchemistry. Fish Res 199:19-25

W Wright PJ, Christensen A, Régnier T, Rindorf A, van Deurs M (2019) Integrating the scale of population processes into fisheries management, as illustrated in the sandeel, Ammodytes marinus. ICES J Mar Sci 76:1453-1463

Submitted: October 11, 2019; Accepted: February 3, 2020 Proofs received from author(s): March 6, 2020 